\title{
THE USE OF GOLD NANOPARTICLE-ANTIBODY CONJUGATES IN IMMUNE TEST FOR MICROCYSTIN-LR DETECTION
}

\author{
${ }^{1}$ Elena A. ZVEREVA, ${ }^{1}$ Olga D. HENDRICKSON, ${ }^{1}$ Anatoly V. ZHERDEV, ${ }^{1}$ Boris B. DZANTIEV, \\ ${ }^{1,2}$ Sergey A. EREMIN
${ }^{1}$ A.N. Bach Institute of Biochemistry, Research Center of Biotechnology of the Russian Academy of Sciences, Moscow, Russia, zverevaea@yandex.ru \\ ${ }^{2}$ M.V. Lomonosov Moscow State University, Moscow, Russia, saeremin@gmail.com
}

https://doi.org/10.37904/nanocon.2020.3738

\begin{abstract}
Because of unique optical properties and easy complexation with biopolymers, gold nanoparticles (GNPs) are actively used as markers in various analytical systems, in particular, as components of conjugates with antibodies in rapid immunochromatographic test systems (ICTSs). However, the choice of the most effective conjugates is often empirical. We compared the possibilities of direct sorption immobilization of antibodies on the surface of GNPs and indirect immobilization through the binding of native-specific antibodies to immobilized antispecies antibodies. The work was performed using the example of ICTS for the detection of microcystinLR (MC-LR), an extremely dangerous phycotoxin produced by microalgae that contaminates drinking water, fish, and seafood. The formats of ICTS with direct and indirect labeling of specific antibodies were compared. It has been shown that indirect labeling provides a lower limit of detection (LOD) for MC-LR than the direct one (the LODs for visual assessment of the results were $0.2 \mathrm{ng} / \mathrm{mL}$ and $1 \mathrm{ng} / \mathrm{mL}$, respectively). The duration of the assay was $20 \mathrm{~min}$. The advantages of ICTSs were shown by comparison with a homogeneous MC-LR immunoassay based on fluorescence polarization detection. It was found that the limit of detection of MC-LR for the last assay is $7.5 \mathrm{ng} / \mathrm{mL}$ despite the equilibrium of immune interactions. The data obtained confirm the advantages of using indirect immobilization of antibodies on the surface of GNPs, which preserves the functional properties of bound molecules.
\end{abstract}

Keywords: Gold nanoparticles, lateral flow immunoassay microcystin, food safety

\section{INTRODUCTION}

Nanoparticles are actively used in a wide range of bioanalytical systems [1]. Their advantages as markers and carriers are due to the large total surface area of suspensions, the possibilities of various methods of conjugation with molecules of different natures, varying sizes and shapes, and the implementation of various highly sensitive detection methods. Among the nanoparticles, gold nanoparticles (GNPs) are especially popular because of their unique optical properties determined by the effect of surface plasmon resonance, simple adsorption and covalent immobilization of various biopolymers, and high stability of the obtained conjugates. In particular, because of this, gold nanoparticles have become the most widely used marker in immunochromatographic test systems (ICTSs)—effective means for out-of-laboratory diagnostics and control [2]. However, despite the large number of developments focused on GNPs and their conjugates, their choice for analytical use is usually made on the basis of empirical recommendations. Thus, in the production of reagents for ICTSs, adsorption immobilization dominates, although in recent years data have been obtained that demonstrate a significant-up to $87 \%$-inactivation of adsorbed antibodies [3].

To overcome these problems, eliminate the loss of specific reagents, and achieve high sensitivity of ICTSs, we consider indirect immobilization of antibodies [4]. Namely, the conjugate of specific antibodies with GNPs 
is replaced by a combination of native-specific antibodies and a universal reagent-a conjugate of antispecies antibodies with GNPs. In some cases, such a replacement allows for reduction of the consumption of specific antibodies and the detection limit of ICTSs by two orders of magnitude; however, this gain varies considerably when passing from one system to another [5,6]. Various explanations have been proposed for the mechanisms that provide the benefits of indirect immobilization [7-9]. In this situation, further characterization of new ICTSs with indirect immobilization of antibodies is required, including a comparison of reagents based on GNPs obtained by direct and indirect immobilization.

In the presented work, such a comparative analysis of two methods of immobilization and ICTSs implemented with their use, as well as an alternative rapid immunoassay format based on the registration of fluorescence polarization, was carried out using the example of the microcystin-LR (MC-LR) immunoassay. MC-LR is a heptacyclic peptide toxin synthesized by cyanobacteria. Anthropogenic impacts on the marine ecosystems have led to a significant increase in eutrophication and the risk of contamination of water resources [10]. The subsequent movement of toxins along the food chains leads to risk of consuming contaminated fish and seafood. The negative consequences of consuming contaminated water and foods include toxic effects (hepato- and nephrotoxicity), endocrine and skin diseases [10,11]. Therefore, there are regulatory requirements for permissible levels of MC-LR. Thus, for drinking water, the World Health Organization states that the total MC-LRs levels should be $<1 \mu \mathrm{g} / \mathrm{L}$. Monitoring of water and food for compliance with these requirements necessitates the need for rapid and sensitive analytical methods. For these purposes, various immunoanalytical methods, including ICTSs [12,13], are being actively developed.

The aim of this study was to compare the capabilities of different rapid immunoanalytical systems for detecting MC-LR, including systems with different conjugates of nanoparticles.

\section{MATERIALS AND METHODS}

\subsection{Preparation and characterization of GNPs}

GNPs with an average diameter of $30 \mathrm{~nm}$ were obtained via citrate reduction of chloroauric acid as described in [14]. Their size was estimated by transmission electron microscopy on a JEM-100C microscope (JEOL, Tokyo, Japan). The obtained images were processed using the Image Tool program.

\subsection{Antibodies immobilization on the GNPs}

Monoclonal antibodies against MC-LR from Eximio Biotec (Hangzhou, Zhejiang, China) and antimouse polyclonal antibodies from Arista Biologicals (Allentown, PA, USA) were used in the study. First, the antibodies were dialyzed against Tris buffer $(0.01 \mathrm{M}, \mathrm{pH} 8.5)$. Then the antibodies were added to the GNP solution adjusted to the same $\mathrm{pH}$. The reactants' ratios were $8.5 \mu \mathrm{g}$ of monoclonal antibodies per $1 \mathrm{~mL}$ of the GNP solution, or $6 \mu \mathrm{g}$ of polyclonal antibodies per $1 \mathrm{~mL}$ of the GNP solution. The mixture was incubated at room temperature for $45 \mathrm{~min}$ and stabilized by bovine serum albumin (BSA) with its final $0.25 \%$ concentration for an additional $15-\mathrm{min}$ incubation. The conjugates were separated by centrifugation $\left(4^{\circ} \mathrm{C}, 13,400 \mathrm{~g}, 15 \mathrm{~min}\right)$ and stored at $4^{\circ} \mathrm{C}$.

\subsection{Preparation of immunochromatographic tests}

Reagents were immobilized on nitrocellulose membrane CNPC-15 (Advanced Microdevices, Ambala Cantt, India) using an Iso-Flow dispenser (Imagene Technology, Hanover, NH, USA). The load of the MC-LR-BSA conjugate (the analytical zone) and anti-mouse polyclonal antibodies (the control zone) was $0.75 \mathrm{mg} / \mathrm{mL}$. The GNP-antibody conjugate was applied onto a glass fiber membrane at D520 $=0.5$ (direct ICTS) and 2.0 (indirect ICTS). The volumes of the loading solutions were $32 \mu \mathrm{L}$ per $1 \mathrm{~cm}$ of the test strip. The assembled membranes were cut into strips and stored in sealed bags at low humidity and room temperature. 


\subsection{Immunochromatographic assay}

For direct format: solutions of MC-LR or tested samples were added to wells, test strips were immersed, and 15-min incubation was performed. For indirect format: solutions of MC-LR or tested samples were mixed with the anti-MC-LR antibodies ( $200 \mathrm{ng} / \mathrm{mL})$ at equal volumes and incubated $3 \mathrm{~min}$, test strips were immersed, and 17-min incubation was performed. Images of the test strips were registered using a flatbed scanner, and the GNPs-caused coloration was accessed using the TotalLab software and compared with the calibration curve.

\subsection{Modification of MC-LR by fluorescein derivative}

$\mathrm{N}, \mathrm{N}^{\prime}$-Dicyclohexylcarbodiimide (DCC) and $\mathrm{N}$-hydroxysuccinimide (NHS) were dissolved in $\mathrm{N}, \mathrm{N}$ dimethylformamide $(0.5 \mathrm{~mL})$ and added to $M C$-LR under nitrogen. The molar ratio of reagents MC$\mathrm{LR} / \mathrm{NHS} / \mathrm{DCC}=1: 16: 16$. The mixture was stirred for $3 \mathrm{~h}$ and ethylenediamine fluorescein thiocarbamyl (EDF) was added (MC-LR/EDF=1:1) for the following 1-h incubation. The reaction mixture was separated by thinlayer chromatography (TLC) in a mixture of $\mathrm{CHCl}_{3}$ and $\mathrm{CH}_{3} \mathrm{OH}(\mathrm{v}: \mathrm{V}=4: 1)$. The band with $\mathrm{Rf} 0.1$ was extracted with $\mathrm{CH}_{3} \mathrm{OH}$ and purified again by the TLC. The final preparation was stored as methanol solution at $4^{\circ} \mathrm{C}$.

\subsection{Polarization fluorescent immunoassay (PFIA)}

The reactions were carried out in borate buffer, $\mathrm{pH}$ 8.0. For the assays, MC-LR solutions (tested samples), MC-LR conjugate with EDF, and antibodies were mixed at equal volumes, incubated for 2-3 min at room temperature, and fluorescence polarization and intensity were measured.

\section{RESULTS AND DISCUSSION}

\subsection{Preparation and characterization of immunoreagents for ICTSs}

The GNPs were synthesized via the most commonly used gold salt reduction by citrate. The obtained preparations were characterized by transmission electron microscopy. The GNPs images and data of their processing demonstrate the absence of aggregates and similar shape of the particles, close to spherical (Figure 1). The average diameter of the GNPs preparation was $31.7 \mathrm{~nm}$. The GNPs demonstrated low variability of size; the RSD value for the diameter was $5.6 \mathrm{~nm}$. Stability of the preparations under storage demonstrates the possibility of using them for conjugation with antibodies.
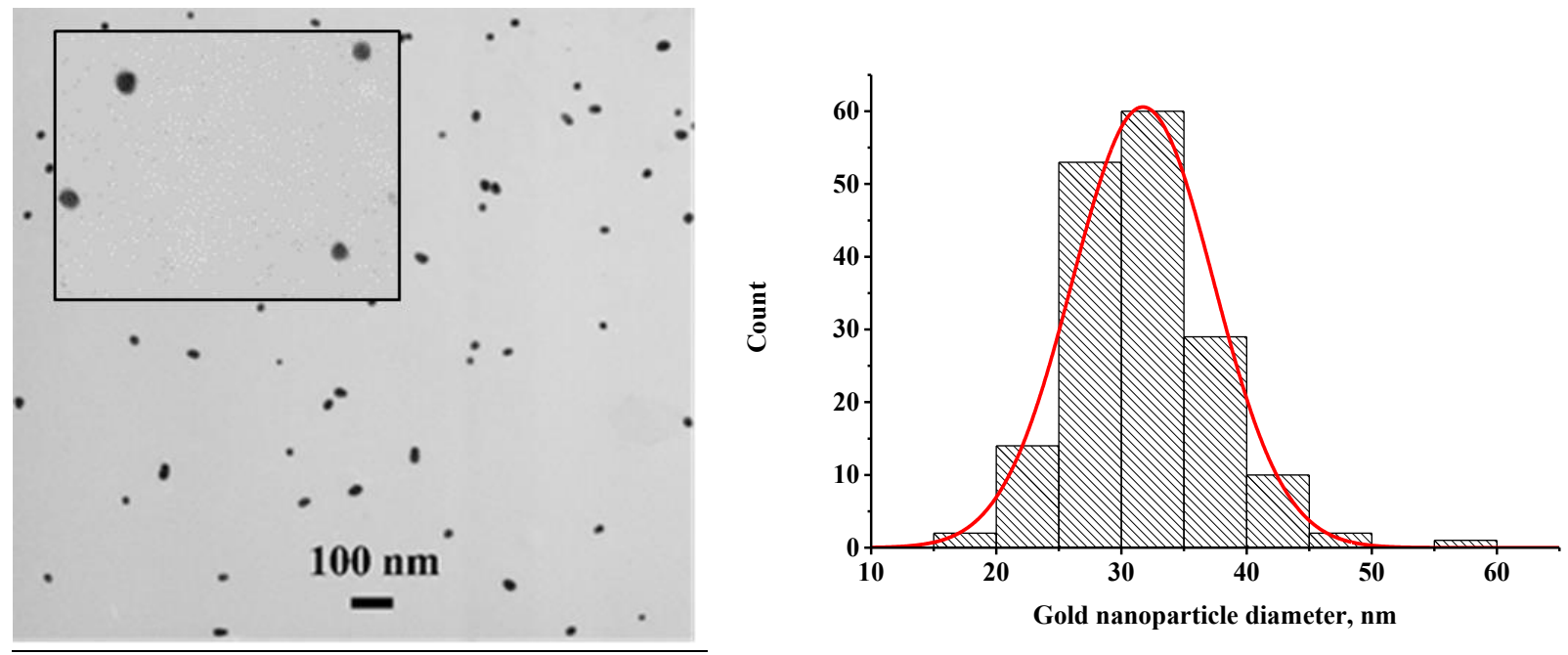

Figure 1 Fragment of GNP microphotograph (including zoom for individual particles) and histogram of particle diameter distribution 
GNPs conjugates with specific and antispecies antibodies were obtained. To find the necessary concentrations of the antibodies, their adsorption isotherms were obtained. Namely, the dependence of D580 from the antibodies concentration was registered after the reactants were mixed and $10 \% \mathrm{NaCl}$ solution was added. An example of the obtained dependence for the anti-MC-LR antibodies is given in Figure 2 . The point of plateau reaching was interpreted as saturation for binding sites for the adsorption immobilization providing stability of the GNPs colloidal solution. At the plateau point, only half of the GNPs surface is covered, but further increase of the loading does not lead to growth of binding capacity for the antibodies after immobilization, as was demonstrated by our previous studies. Based on the data from these experiments, we have chosen the concentration of anti-MC-LR antibodies equal to $8.5 \mu \mathrm{g} / \mathrm{mL}$ and the concentration of antispecies antibodies equal to $6 \mu \mathrm{g} / \mathrm{mL}$ as optimal for further preparative syntheses.

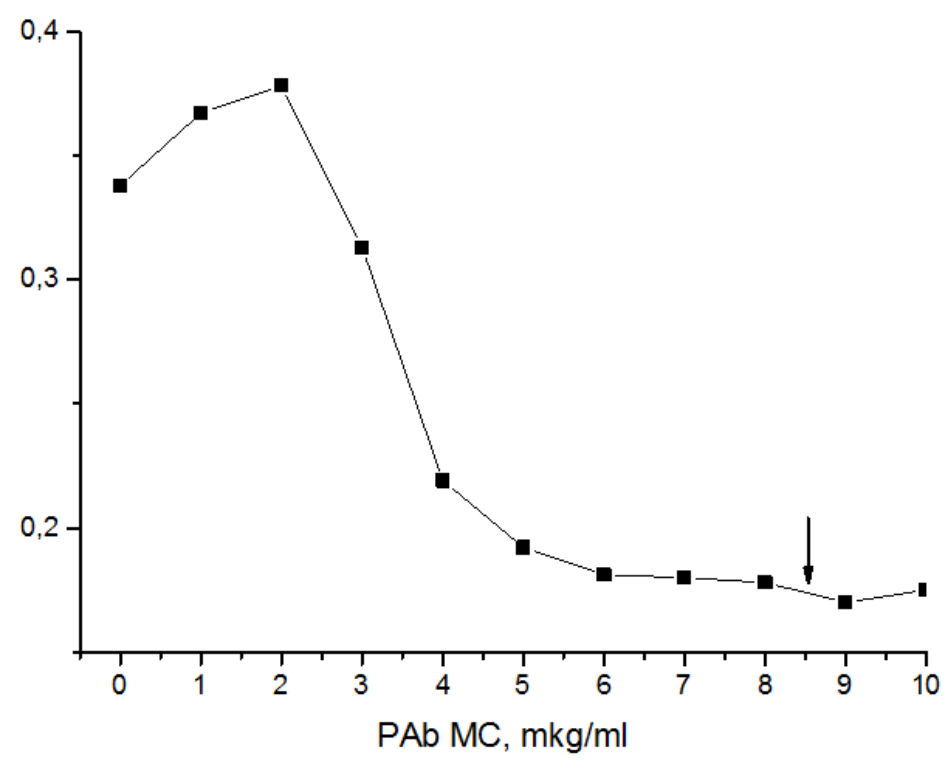

Figure 2 Choice of the concentration of specific antibodies used for conjugation with GNPs (D520 = 1.0).

The selected antibody concentration $(8.5 \mu \mathrm{g} / \mathrm{mL})$ is marked by arrow

\subsection{The development and characterization of direct format of ICTS for MC-LR detection}

In this ICTS, the MC-LR molecules potentially contained in the tested sample and the MC-LR-protein conjugate applied on the analytical zone competed for binding with the GNPs-labeled specific antibody applied on a fiberglass membrane. When choosing the reagents concentrations, we considered two demands: intense coloration of binding zones and low limit of detection. Thus, the chosen concentrations were the following: 0.75 $\mathrm{mg} / \mathrm{mL}$ for MC-LR-BSA conjugate and D520 $=0.5$ for the antibody-GNP conjugate.

The resulting ICTS demonstrated a visual limit of detection equal to $10 \mathrm{ng} / \mathrm{mL}$ and instrumental limit of detection equal to $5 \mathrm{ng} / \mathrm{mL}$. Duration of the assay was $15 \mathrm{~min}$. It should be noted that the time of liquid movement along the test strip was much shorter (about 7-8 $\mathrm{min}$ ), but for better reproducibility, additional time was necessary to reach higher coloration of the bound GNPs.

\subsection{The development and characterization of indirect format of ICTS for MC-LR detection}

The approach of indirect labeling in the ICTSs is based on the competition of the MC-LR molecules in the sample and the applied MC-LR-protein conjugate for binding with native-specific antibodies. The formed complexes are then labeled by the GNP-antispecies antibodies conjugate. In this way, all specific antibodies are involved in the competition, and their quantity may be reduced without loss of the detected signal. Moreover, each antigen molecule in the tested sample decreases the detected optical signal (exclusion of 
nonproductive binding with several antibody molecules immobilized at the same GNP without decrease of the registered coloration). The assay format was optimized based on the same rules as in the previous case. Thus, Figure $\mathbf{3}$ demonstrates variations of the concentrations of specific antibodies in the range of $1.8-0.1 \mu \mathrm{g} / \mathrm{mL}$, with the corresponding decreases of coloration intensity. The chosen optimal parameters for the test strip preparation were the following: immobilization of antispecies antibodies at a concentration of $0.5 \mathrm{mg} / \mathrm{mL}$, MC-LR-BSA conjugate applying at a concentration of 0.75 $\mathrm{mg} / \mathrm{mL}$, and the use of GNPs conjugated with the antispecies antibodies in a concentration that accords with D520 $=2.0$.

The assay under the chosen conditions demonstrated the visual detection limit of 1 $\mathrm{ng} / \mathrm{mL}$, whereas the instrumental detection limit was $0.2 \mathrm{ng} / \mathrm{mL}$. Thus, a five- to tenfold improvement of the analytical parameters was reached. The assay time was equal to 20 min (including 3 min of starting incubation i).

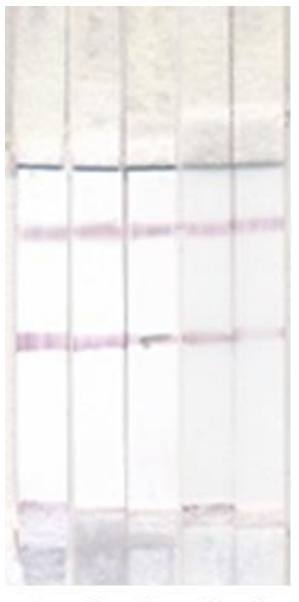

$\begin{array}{lllll}1 & 2 & 3 & 4 & 5\end{array}$

Figure 3 ICTSs (indirect format) after the assay. Test strips 1-5 correspond to concentrations of specific antibodies: $1.8 \mu \mathrm{g} / \mathrm{mL} ; 0.9 \mu \mathrm{g} / \mathrm{mL} ; 0.4 \mu \mathrm{g} / \mathrm{mL} ; 0.2 \mu \mathrm{g} / \mathrm{mL}$; and $0.1 \mu \mathrm{g} / \mathrm{mL}$, respectively

\subsection{PFIA of MC-LR}

The PFIA is a homogeneous analytical technique (without separation and washing) that is based on the competitive binding of controlled and fluorophore-labeled analyte molecules with specific antibodies and the measurement of fluorescence polarization value that depends on the analyte content in the sample.

Optimization of the competitive FPIA conditions included the choice of antibody concentration and the content of the reaction media. It was demonstrated that the antibody dilution of 1:600 provided a stable analytical signal and maximum assay sensitivity. Increased dilution of antibodies resulted in a significant decrease in signal stability. Two tested sets of prepared reactants demonstrated limits of detection equal to 20 and $7.5 \mathrm{ng} / \mathrm{mL}$. Linearity ranges for these completions were $58-470 \mathrm{ng} / \mathrm{mL}$ and $15-125 \mathrm{ng} / \mathrm{mL}$, respectively. Thus, even the best completion of reactants for PFIA demonstrated worse sensitivity compared to ICTSs (instrumental detection), despite the equilibrium conditions of immune interactions. This difference confirms preference GNPs as efficient optical labels for immunoanalytical techniques.

\section{CONCLUSION}

Results of the implemented comparative study (summarized in Table 1) confirm advantages of ICTSs as efficient tools for rapid sensitive testing. However, common immunochromatographic protocol is associated with the inactivation of some part of specific antibodies after their immobilization. The use of the indirect format of ICTSs precludes this problem and provides oriented immobilization of the specific antibodies and the possibility of reducing their quantity used per assay. Therefore, the further application of this approach to other ICTSs seems reasonable.

Table 1 Comparison of analytical parameters for the developed immunoassays of MC-LR.

\begin{tabular}{|c|c|c|c|}
\hline Analysis & $\begin{array}{c}\text { Instrumental limit of } \\
\text { detection, } \mathbf{n g} / \mathbf{m L}\end{array}$ & $\begin{array}{c}\text { Visual limit of detection, } \\
\mathbf{n g} / \mathbf{m L}\end{array}$ & Analysis time, min \\
\hline Direct format of ICTSs & 5.0 & 10.0 & 15 \\
\hline Indirect format of ICTSs & 0.2 & 1.0 & 20 \\
\hline PFIA & 7.5 & - & 20 \\
\hline
\end{tabular}




\section{ACKNOWLEDGEMENTS}

\section{This study was supported by the Russian Scientific Foundation (project 20-43-07001). The authors are grateful to S.M. Pridvorova (Research Center of Biotechnology) for TEM experiments.}

\section{REFERENCES}

[1] NOAH, N.M., NDANGILI, P.M. Current trends of nanobiosensors for point-of-care diagnostics. Journal of Analytical Methods in Chemistry. 2019, pp. 2179718.

[2] HUANG, X., AGUILAR, Z.P., XU, H., LAI, W., XIONG, Y. Membrane-based lateral flow immunochromatographic strip with nanoparticles as reporters for detection: A review. Biosensors \& Bioelectronics. 2016, vol. 75, pp. 166180.

[3] TRIPATHI, K., DRISKELL, J.D. Quantifying bound and active antibodies conjugated to gold nanoparticles: A comprehensive and robust approach to evaluate immobilization chemistry. ACS Omega. 2018, vol. 3, no. 7, pp. 8253-8259.

[4] URUSOV, A.E., ZHERDEV, A.V., DZANTIEV, B.B. Use of gold nanoparticle-labeled secondary antibodies to improve the sensitivity of an immunochromatographic assay for aflatoxin B1. Microchimica Acta. 2014. vol. 181, pp. 1939-1946.

[5] PETRAKOVA, A.V., URUSOV, A.E., GUBAYDULliNA, M.K., BARTOSH, A.V., ZHERDEV, A.V., DZANTIEV, B.B. "External" antibodies as the simplest tool for sensitive immunochromatographic tests. Talanta. 2017, vol. 175, pp. 77-81.

[6] HENDRICKSON, O.D., ZVEREVA, E.A., POPRAVKO, D.S., ZHERDEV, A.V., XU, C., DZANTIEV, B.B. An immunochromatographic test system for the determination of lincomycin in foodstuffs of animal origin. Journal of Chromatography B. 2020, vol. 1141, article 122014.

[7] BERLINA, A.N., BARTOSH, A.V., SOTNIKOV, D.V., ZHERDEV, A.V., XU, C., DZANTIEV, B.B. Complexes of gold nanoparticles with antibodies in immunochromatography: comparison of direct and indirect immobilization of antibodies for the detection of antibiotics. Nanotechnologies in Russia. 2018, vol. 13, pp. 430-438.

[8] DI NARDO, F., CAVALERA, S., BAGGIANI, C., GIOVANNOLI, C., ANFOSSI, L. Direct vs mediated coupling of antibodies to gold nanoparticles: the case of salivary cortisol detection by lateral flow immunoassay. ACS Applied Materials \& Interfaces. 2019, vol. 11, no. 36, pp. 32758-32768.

[9] URUSOV, A.E., PETRAKOVA, A.V., ZHERDEV, A.V., ZVEREVA, E.A. Indirect labeling of antibodies as a universal approach to increase sensitivity of lateral flow tests: A case study for mycotoxins detection. The Open Biotechnology Journal. 2019, vol. 13, pp. 113-121.

[10] PREECE, E.P., HARDY, F.J., MOORE, B.C., BRYAN, M. A review of microcystin detections in Estuarine and Marine waters: Environmental implications and human health risk. Harmful Algae. 2017, vol. 61, pp. 31-45.

[11] GURBUZ, F., UZUNMEHMETOĞLU, O.Y., DILER, Ö., METCALF, J.S., CODD, G.A. Occurrence of microcystins in water, bloom, sediment and fish from a public water supply. Science of the Total Environment. 2016, vol. 562, pp. 860-868.

[12] LIU, Y., JI, J., CUI, F., SUN, J., WU, H., PI, F., ZHANG, Y., SUN, X. Development of a two-step immunochromatographic assay for microcystin-LR based on fluorescent microspheres. Food Control. 2019, vol. 95, pp. 34-40.

[13] AKTER, S., KUSTILA, T., LEIVO, J., MURALITHARAN, G., VEHNIAINEN, M., LAMMINMAKI, U. Noncompetitive chromogenic lateral-flow immunoassay for simultaneous detection of microcystins and nodularin. Biosensors. 2019, vol. 9, no. 2, pp. 14672-14685.

[14] FRENS, G. Controlled nucleation for the regulation of the particle size in monodisperse gold suspensions. Nature Physical Science. 1973, vol. 241, pp. 20-23. 